\title{
Design and Application of Thermal Crack Control in Mass Concrete
}

\author{
Chao Li \\ Department of Railway Engineering, Liaoning Railway Vocational and Technical College, Jinzhou, \\ China \\ 5139007@qq.com
}

Keywords: Mass concrete; Temperature measurement; Cracking control

\begin{abstract}
According to the unique characteristics of foundation structure design and incorporating with the practice of a construction of mass concrete foundation, mass concrete material selection, mixture ratio design, pouring and curing technology, temperature measurement and control technology are presented in this paper. The entire temperature difference and temperature stress theoretical calculation process are also presented. Because comprehensive technology measures were taken, the mass concrete of this foundation structure was continuously poured, no later-poured belt or construction joint reserved. By later observation, no harmful crack was found, the concrete quality was fine, and the project quality was therefore ensured.
\end{abstract}

\section{Introduction}

The raft foundation of a tall building was designed to mass waterproof concrete with $\mathrm{C} 40$ strength grade and seepage resistance grade P12, the thickness of the foundation was 1.8 2.4 meters, even 3.2 meters in some areas, so it is a typical mass concrete construction. For the concrete was pouring in June, the environmental temperature was high.

The foundation was originally designed to the size of $48 \times 36$ meters, and with two crossing postpouring belts. As the concrete seepage resistance was high, it was inappropriate to set any post-pouring belts. After negotiation with the parties concerned, the post-pouring belts were canceled, and the foundation concrete was poured continuously.

For the purpose to reduce the dosage of cement and the hydration heat, and making full use of the late strength After negotiation with the parties concerned, the strength of 60 ages concrete was adopted as standard.

\section{Material Selection and Mixture Ratio Design}

The hydration heat of mass concrete does not emanate easily, so the material selection and mixture ratio design not only met the requirements of strength and seepage resistance, but also had the ability to resist crack development.

Cement Selection. After careful consideration, the Portland Cement was selected, because the hydration heat of $\mathrm{C}_{3} \mathrm{~A}$ reach up to $70 \%$ of the total cement hydration heat, it is necessary to control the content of $\mathrm{C}_{3} \mathrm{~A}$. Finally, some brand $\mathrm{P} \cdot \mathrm{O} 42.5$ cement was selected, which content of $\mathrm{C}_{3} \mathrm{~A}$ was under $7 \%$.

Aggregate Selection. Sand: one type of local medium sand was used to mix the concrete which was hard and with good gradation. the contents of clay below $1 \%$, and the fineness modulus was $2.5 \sim 3.2$ gravel: one type of local low-alkali gravel was selected, which gradation form $10 \mathrm{~mm}$ to $31.5 \mathrm{~mm}$, and air void less than $1 \%$, also flat and elongated particle content less than $10 \%$.

Fly Ash Selection. Fly ash could improve the performance of cement, especially effectively reduce the total heat of hydration of cement, and therefore effectively restrained the temperature crack development. So some highly reactive fly ash from local power plants was selected. 
Admixture Selection. Composite micro-expanding agent UEA was added to the concrete, the UEA could generate pre-stress by proper expansion, and this pre-stress can counteract some tensile stress. But concrete slump loss would be higher after adding UEA, so the WDN-7 series high range water reducing agent must be added at same time, which could meet the requirement of pumping concrete slump.

Water Selection. Underground water was pumped to mix the concrete, for it was cool, and by experiment, the water met all the quality requirements from JGJ63-2006.and 10 degrees lower than the tap water's temperature, so it could effectively reduce the concrete initial temperature.

Final Mixture Ratio. According to the priority of: strength $\rightarrow$ impermeability and durability $\rightarrow$ low hydration heat and volume stability $\rightarrow$ pumping performance, also after a lot of experiments. The final mixture ratio of $\mathrm{C} 40$ ( $\mathrm{R} 60) \mathrm{P} 12$ concrete was determined, as shown in Table1.

Table 1 Mixture Ratio[kg/m $\left.\mathrm{m}^{3}\right]$

\begin{tabular}{|l|l|l|l|l|l|l|l|}
\hline Water & Cement & Sand & Gravel & Fly ash & UEA & WDN-7 & Sand ratio (\%) \\
\hline 190 & 296 & 785 & 1129 & 154 & 50 & 9 & 41 \\
\hline
\end{tabular}

Note: the concrete slump was $(160 \pm 20) \mathrm{mm}$, water to binder ratio was 0.38 , the initial setting time was 10 hours and final setting time was form 12 to 14 hours.

\section{Temperature Crack Control Calculation}

Based on the finite element method, both the temperature field and the temperature stress were calculated, To save some space, only the calculation results was shown in table 2 and table 3.

Table 2 Temperature Crack Control Calculation Results of Foundation Mass Concrete at "t" Ages

\begin{tabular}{|l|l|l|l|l|l|l|l|l|l|l|}
\hline $\mathrm{t}$ & 3 & 6 & 9 & 12 & 15 & 18 & 21 & 24 & 27 \\
\hline $\mathrm{T}_{1(\mathrm{t})}$ & 80.41 & 66.49 & 61.27 & 57.09 & 50.16 & 45.08 & 41.73 & 38.94 & 36.7 & 35.59 \\
\hline $\mathrm{T}_{2(\mathrm{t})}$ & 67.37 & 56.67 & 52.65 & 49.44 & 44.16 & 40.21 & 37.63 & 35.48 & 33.77 & 32.91 \\
\hline $\mathrm{T}_{\mathrm{m}(\mathrm{t})}$ & 73.89 & 61.58 & 56.96 & 53.27 & 47.16 & 42.65 & 39.68 & 37.21 & 35.24 & 34.25 \\
\hline $\mathrm{E}(\mathrm{t})$ & 0.77 & 1.36 & 1.8 & 2.15 & 2.41 & 2.6 & 2.76 & 2.88 & 2.96 & 3.03 \\
\hline$\beta_{(t)}$ & 4.33 & 2.45 & 1.85 & 1.55 & 1.37 & 1.28 & 1.21 & 1.16 & 1.13 & 1.1 \\
\hline$\varepsilon_{\mathrm{Y}(\mathrm{t})}$ & 1.1 & 2.19 & 3.24 & 3.33 & 5.24 & 6.19 & 7.12 & 8.02 & 8.9 & 9.74 \\
\hline $\mathrm{T}_{\mathrm{Y}(\mathrm{t})}$ & 1.1 & 2.19 & 3.24 & 3.33 & 5.24 & 6.19 & 7.12 & 8.02 & 8.9 & 9.74 \\
\hline
\end{tabular}

Note :t-Concrete age (d);

$\mathrm{T}_{1(\mathrm{t})}-$ Calculated temperature of concrete core at " $\mathrm{t}$ " age $\left({ }^{\circ} \mathrm{C}\right)$;

$\mathrm{T}_{2(\mathrm{t})}$ Calculated temperature of concrete surface at " $\mathrm{t}$ " age $\left({ }^{\circ} \mathrm{C}\right)$;

$\mathrm{T}_{\mathrm{m}(\mathrm{t})}$ Calculated internal average temperature of concrete at " $\mathrm{t}$ " age $\left({ }^{\circ} \mathrm{C}\right)$;

$\mathrm{E}_{(\mathrm{t})} \longrightarrow$ Calculated modulus of elasticity of concrete at " $\mathrm{t}$ " age $\left(\mathrm{N} / \mathrm{mm}^{2}\right)$;

$\beta_{(\mathrm{t})}-$ Foundation restraint coefficient of concrete at " $\mathrm{t}$ " age $(1 / \mathrm{mm})$;

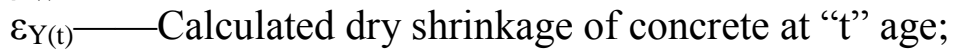

$\mathrm{T}_{\mathrm{Y}(\mathrm{t})}$ Calculated temperature difference during dry shrinkage of concrete at " $\mathrm{t}$ " age $\left({ }^{\circ} \mathrm{C}\right)$.

Table 3 Temperature Crack Control Calculation Results in the Number "I" Time Interval

\begin{tabular}{|l|l|l|l|l|l|l|l|l|l|}
\hline $\mathbf{i}$ & $\mathbf{1}$ & $\mathbf{2}$ & $\mathbf{3}$ & $\mathbf{4}$ & $\mathbf{5}$ & $\mathbf{6}$ & $\mathbf{7}$ & $\mathbf{8}$ & $\mathbf{9}$ \\
\hline$\Delta \mathrm{T}_{\mathrm{i}}$ & 13.4 & 5.67 & 3.78 & 8.02 & 5.46 & 3.90 & 3.37 & 2.85 & 1.83 \\
\hline$\overline{E_{i}}$ & 1.06 & 1.58 & 1.98 & 2.28 & 2.51 & 2.68 & 2.82 & 2.92 & 3.00 \\
\hline$\overline{\beta_{i}}$ & 3.39 & 2.15 & 1.70 & 1.46 & 1.33 & 1.25 & 1.19 & 1.15 & 1.12 \\
\hline$\overline{s_{i}}$ & 0.55 & 0.50 & 0.46 & 0.43 & 0.40 & 0.38 & 0.36 & 0.35 & 0.33 \\
\hline$\sigma_{\mathrm{i}}$ & 0.21 & 0.12 & 0.09 & 0.21 & 0.15 & 0.11 & 0.09 & 0.08 & 0.05 \\
\hline
\end{tabular}


Note: $\mathrm{i}$ - Time interval number, divided by 3 days during concrete strength development;

$\Delta \mathrm{Ti} \longrightarrow$ Calculated temperature difference in the number "i" time interval $\left({ }^{\circ} \mathrm{C}\right)$;

$\overline{E_{i}} \longrightarrow$ Calculated average modulus of elasticity in the number " $\mathrm{i}$ " time interval $\left(\mathrm{N} / \mathrm{mm}^{2}\right)$;

$\overline{\beta i} \_$Calculated average foundation restraint coefficient in the number " $\mathrm{i}$ " time interval $(1 / \mathrm{mm})$;

$\overline{s i} \_$Calculated average stress relaxation coefficient in the number "i" time interval;

${ }_{\sigma i} \quad$ Calculated tensile stress in the number "i" time interval $\left(\mathrm{N} / \mathrm{mm}^{2}\right)$.

The maximum tensile stress at some specified time of concrete age was $\sigma_{\max }$, and its calculating formula shown as follows:

$$
\sigma_{\max }=[1 /(1-v)] \sum_{i=1}^{n} \sigma_{i}=1.31 \mathrm{~N} / \mathrm{mm}^{2}
$$

Note: $v \longrightarrow$ Poisson's ratio, it was 0.15 here.

Anti-crack safety coefficient was $\mathrm{K}$, and its calculating formula shown as follows:

$$
K=f_{t} / \sigma_{\max }
$$

Note: $\mathrm{f}_{\mathrm{t}}$ Concrete tensile strength design value at some specified time of concrete age $\left(\mathrm{N} / \mathrm{mm}^{2}\right)$

Because the foundation concrete strength grade had changed into C40(R60), the actual concrete strength at 28 ages was estimated as C35 concrete, so the value of " $\mathrm{ft}$ from the formula above was found from tables, it was $1.65 \mathrm{~N} / \mathrm{mm}^{2}$. So the value of $\mathrm{K}$ shown as follows:

$$
K=1.65 / 1.31=1.26>1.15
$$

The anti-crack safety coefficient $K=1.26>1.15$, that met the requirements of anti-cracking performance, therefore the calculation results above proved the theoretical possibility of foundation mass concrete continuous pouring.

\section{Construction and Curing Measures}

Construction Measures. As mentioned, the post-pouring belts were canceled, the slope pouring method was adopted, so the foundation mass concrete was poured in 3 layers, the thickness of each layer was not exceeding $600 \mathrm{~mm}$ with the slope between $1 / 6 \sim 1 / 10$, if in some thicker parts such as the elevator shaft, the thickness of each layer was not exceeding $800 \mathrm{~mm}$.

According to the natural slope of pumping concrete, three vibrators were set around every concrete outlet. The first vibrator was set near the outlet, while the second was at the central place of the slope, and the last one was at the foot of the slope, each vibrator was operated by specific worker.

The bleeding of mass pumping concrete during poring must be cleaned up to ensure concrete quality, For this reason, when the slope foot concrete reaching the side form ,the concrete must be poured along the side form, therefore, a puddle was formed. Then the bleeding could be pumped out by the hose pump, but the laitance should not be pumped, for it was easily damage the pumping system.

In general the cement paste on the surface of mass concrete was too much, which could cause shrinkage crack. To avoid that, a steel wire mesh by 4 @100 was pushed 20mm under concrete surface during concrete pouring. With the wood float used to rub pressure level off, and repeated again before final set, the concrete shrinkage crack could be closed.

Curing Measures. In order to reduce the temperature difference between surface and core of this foundation mass concrete during curing stage, the technical measures of surface heat and moisture insulation was adopted, the specific operation was that firstly a layer of impermeable plastic film was covered on the concrete upper surface after pouring, secondly three layers of straw mattress was also covered on the concrete upper surface, and the covering lasted 30 days after pouring, during that 30days, according to the temperature measuring results, the number of the straw mattress layers would be adjusted timely to reduce the temperature difference. The side forms removing time was also delayed to 20 days after pouring. Also for the purpose of heat preservation, one layer of blanket was 
bound and fixed outside the side forms, while some specific workers were assigned to water the side form daily.

\section{Temperature Measurement}

Owing to the factors of uncertainty remains, it was inevitable that the theoretical calculation can't predict precisely the actual facts. So the mass concrete temperature should be real-time monitored to know the temperature changes, therefore taking appropriate measures to fix it.

The environmental temperature was measured by an ordinary thermometer, while the concrete internal temperature was measured by the type JDC- 2 of construction electronic thermometer. Three sensors from the JDC- 2 were arranged along the façade. Two sensors at the top and the bottom were all set $100 \mathrm{~mm}$ to the concrete upper and lower surface, while the middle sensor was set $0.6 \mathrm{~h}$ to the upper surface, for some study shows that the highest temperature usually appears at the lower half part of the mass concrete, especially during the temperature dropping period. Façade location of the sensors was shown in Fig.1.

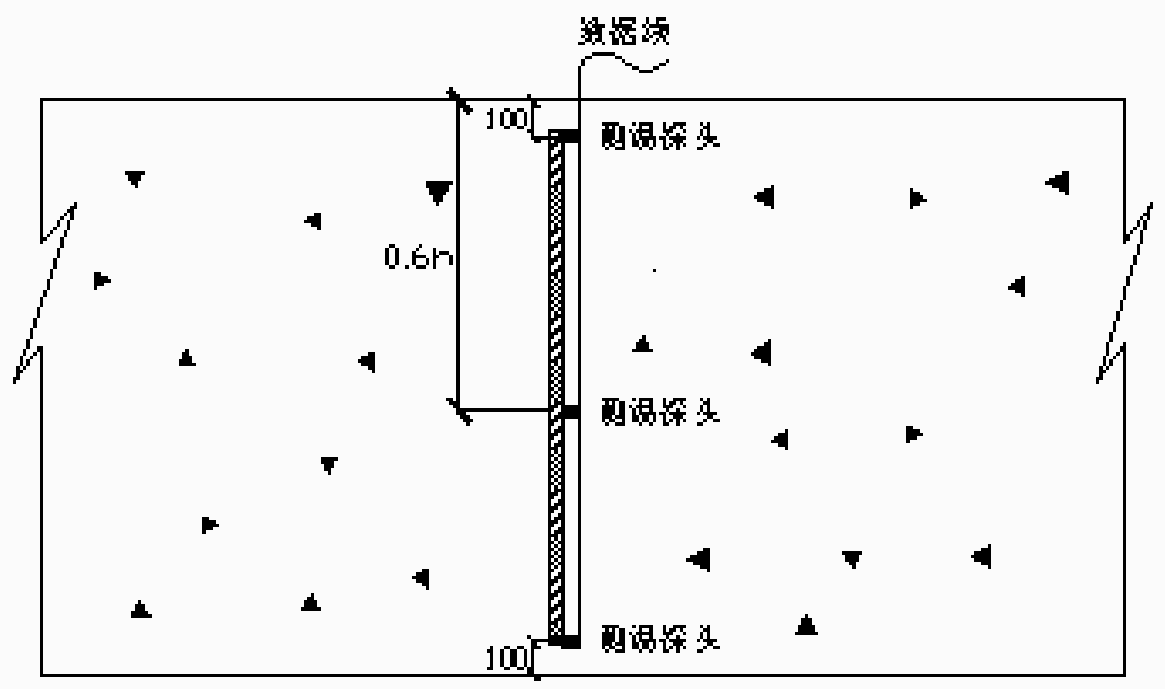

Figure 1. Temperature sensors setting location

There were twenty-eight temperature sensors setting inside the concrete, adding one environmental sensor and three concrete surface sensors, so thirty-two in total.

All the temperatures were measured at 2 hours intervals, and changed into 4 hours intervals after the highest temperature appeared. And the measurement stopped when the core concrete temperature dropping below the initial temperature.

Real-time temperature monitor results showed that the environment temperature was between 16 to 28 degrees Celsius, the concrete initial temperature was between 17 to 23 degrees Celsius, the highest temperature in the concrete core was between 74.7 to 78.5 degrees Celsius, it appeared at 42 hours after pouring, and remained some time. The highest temperature in the concrete surface was between 52.2 to 54.6 degrees Celsius. Based on the real-time temperature monitor results, the maximum temperature difference between the surface and the core was 24.6 degrees, and the maximum temperature difference between the environment and the concrete surface was 23.4 degrees, they were all less than 25 degrees, therefore the control of mass concrete temperature crack was ensured.

According to the actual temperature monitor results, the highest temperature in the concrete core appeared on the second day (42 hours) after pouring which was not the valves ( 3 days) setting in the temperature calculation formula of Building Construction Handbook, and from which all the calculation was based on the time intervals of 3days, so if 2 days or a even shorter time interval was 
adopted in the calculation, with adjusting formulas and coefficient related accordingly, the results would be more close to the real valves.

\section{Conclusion}

Due to appropriate measures and meticulous construction, by months of careful observation, no harmful crack was found, and that building's foundation mass concrete quality met all the requirements. So if only engineers respect the unique characteristics of mass concrete, optimizing the mixture ratio and organizing construction and curing measures carefully, also with a precise temperature measurement, the harmful crack could be completely avoided, therefore the mass concrete continuous pouring ensured.

\section{Acknowledgements}

Project supported by the Research Foundation of Education Bureau of Liaoning Province, China (Grant No.L2015311).

\section{References}

[1] Compile Group, "Building Construction Handbook," Building Industry Press, 2016.

[2] S. Yin, H. Luo, S. Ding, "Real-time implementation of fault-tolerant control systems with performance optimization”, IEEE Transactions on Industrial Electronics, 64(2015):2402-2411. 